\title{
Understanding Postprandial Inflammation and Its Relationship to Lifestyle Behaviour and Metabolic Diseases
}

\author{
Boudewijn Klop, ${ }^{1}$ Spencer D. Proctor, ${ }^{2}$ John C. Mamo, ${ }^{3}$ \\ Kathleen M. Botham, ${ }^{4}$ and Manuel Castro Cabezas ${ }^{1}$ \\ ${ }^{1}$ Department of Internal Medicine, Center for Diabetes and Vascular Medicine, Sint Franciscus Gasthuis, \\ 3004 BA Rotterdam, The Netherlands \\ ${ }^{2}$ Metabolic and Cardiovascular Diseases Lab, Molecular Cell Biology of Lipids Group, Alberta Diabetes and Mazankowski \\ Alberta Heart Institutes, University of Alberta, Edmonton, AB, Canada T6g2R3 \\ ${ }^{3}$ Faculty of Health Sciences, Curtin University, Perth and Sydney, WA 6102, Australia \\ ${ }^{4}$ Department Of Veterinary Basic Sciences, The Royal Veterinary College, London NW1 OTU, UK
}

Correspondence should be addressed to Manuel Castro Cabezas, m.castrocabezas@sfg.nl

Received 23 June 2011; Accepted 29 July 2011

Academic Editor: Karlheinz Peter

Copyright ( 2012 Boudewijn Klop et al. This is an open access article distributed under the Creative Commons Attribution License, which permits unrestricted use, distribution, and reproduction in any medium, provided the original work is properly cited.

\begin{abstract}
Postprandial hyperlipidemia with accumulation of remnant lipoproteins is a common metabolic disturbance associated with atherosclerosis and vascular dysfunction, particularly during chronic disease states such as obesity, the metabolic syndrome and, diabetes. Remnant lipoproteins become attached to the vascular wall, where they can penetrate intact endothelium causing foam cell formation. Postprandial remnant lipoproteins can activate circulating leukocytes, upregulate the expression of endothelial adhesion molecules, facilitate adhesion and migration of inflammatory cells into the subendothelial space, and activate the complement system. Since humans are postprandial most of the day, the continuous generation of remnants after each meal may be one of the triggers for the development of atherosclerosis. Modulation of postprandial lipemia by lifestyle changes and pharmacological interventions could result in a further decrease of cardiovascular mortality and morbidity. This paper will provide an update on current concepts concerning the relationship between postprandial lipemia, inflammation, vascular function, and therapeutic options.
\end{abstract}

\section{Introduction}

Atherosclerosis is the primary cause of death in the world [1]. Classical risk factors such as smoking, hypertension, fasting hyperlipidemia, insulin resistance, increased body fat mass, and unfavourable body fat distribution are strongly interrelated and can often be found in one and the same subject. Subjects with fasting hypertriglyceridemia usually have elevated postprandial lipids due to the close correlation of fasting and postprandial triglycerides (TG) [2]. Postprandial lipemia has gained interest because of recent reports showing that nonfasting TG independently predict the risk for atherosclerosis $[3,4]$ and are possibly even stronger predictors of cardiovascular disease (CVD) than fasting TG $[3,5]$.

Atherosclerosis is considered a low-grade chronic inflammatory disease [6], and both the postprandial phase and chronic disease states such as the metabolic syndrome are associated with increased inflammation. This paper outlines recent developments in the understanding of postprandial inflammation and its relationship with vascular function, metabolic diseases, and lifestyle behaviour.

\section{Metabolism of Postprandial Lipemia}

Dietary fat is absorbed in the intestine and secreted into lymph by enterocytes in TG-rich chylomicrons. Once in the circulation, chylomicrons rapidly undergo hydrolysis to produce cholesterol-dense lipoprotein remnants which are taken up by the liver $[7,8]$. After a fatty meal, exogenous fatty acids are delivered to the liver by chylomicron remnants and may then be reassembled and returned to the blood in very low-density lipoproteins (VLDL) [9]. 
The hypertriglyceridemia observed postprandially is due to raised concentrations of chylomicrons, VLDL, and their respective remnants, collectively known as triglyceride-rich lipoproteins (TRLs).

People in the Western world are nonfasting for most of the day, consequently leading to a continuous challenge of the endothelium by atherogenic lipoprotein remnants [10, 11]. The exogenous chylomicrons and endogenously produced VLDL share the same metabolic pathway, for example, endothelium-bound lipoprotein lipase (LPL), which hydrolyzes TG into glycerol and fatty acids. In the postprandial phase, due to limited LPL availability, competition at the level of this enzyme will occur resulting in accumulation of TRLs. This competition is most likely when fasting hypertriglyceridemia is present. The increased levels of free fatty acids (FFAs) as a result of a hypercaloric diet are regarded as one of the key etiologic components of the metabolic syndrome, type 2 diabetes (T2DM), and obesity $[12,13]$.

\section{Residual Risk of Cardiovascular Disease after LDL Cholesterol Lowering}

Based on results from large clinical trials, lipid management for reducing the risk for CVD has been typically focused on reducing LDL-C by statin therapy [14-18]. Despite aggressive LDL-C lowering by statin therapy, approximately two-thirds of all CVD events remain. These "residual" events appear to be independent of the LDL-C and in recent years have gained momentum as a concept of "residual risk" of CVD. Interestingly, statins do reduce postprandial lipemia and also have an effect on complement, but they do not affect TG sufficiently to be of clinical relevance in hypertriglyceridemic conditions [2, 19-22]. Interestingly, this "residual risk" has been found to be greater for treated patients with diabetes or the metabolic syndrome than in untreated patients without these conditions [23, 24]. One could interpret these observations to infer that statin therapy, resulting in LDL-C lowering, does not necessarily bring the relative CVD risk in patients suffering from diabetes and metabolic syndrome to the level of nondiabetics and patients without metabolic syndrome. Consequently, the current model we propose is that the "residual risk" hypothesis of atherosclerosis is not just dependent on circulating concentrations of LDL-C but is equally dependent on remnant lipoprotein concentrations and perturbations in the arterial vessel wall that influence the rate of arterial lipoprotein retention. The potential impact of the "residual risk" hypothesis is perhaps most appreciated during conditions of increased atherosclerotic risk. For example, subjects with insulin resistance, T1DM, or T2DM showed raised plasma concentrations of fasting remnant lipoproteins and an ensuing impairment in postprandial lipoprotein metabolism $[25,26]$. The remnant lipoproteins are able to penetrate arterial tissue and become entrapped within the subendothelial space [27]. It has also been demonstrated that remnant lipoproteins can induce macrophage lipid loading, which is a hallmark feature of early atherogenesis [2830]. Moreover, raised fasting concentrations of apoB48, the specific protein of chylomicrons and their remnants [31], have been shown to be elevated in patients with obesity, insulin-resistance, and T2DM [32-35]. Numerous studies have shown that fasting levels of remnant lipoproteins can predict impaired metabolism of chylomicrons, particularly in those at risk of CVD [36-38]. Under experimental conditions, some studies have suggested that the small LDL particles may have a higher rate of delivery but in turn efflux more readily from arterial tissue compared to remnant lipoproteins $[39,40]$. However, despite many studies showing atherogenic effects of impaired postprandial lipemia, it remains uncertain whether lowering postprandial lipemia would reduce CVD risk or if TG are merely a marker of other metabolic abnormalities [41]. But it is certain that postprandial lipemia, obesity, insulin resistance, inflammation, and vascular function and atherogenesis are closely related with each other.

\section{Postprandial Lipemia and Vascular Integrity}

Coronary arteries are characterized by tightly apposed endothelial cells with significant expression of tight junction proteins [42]. In healthy vessels, the coronary endothelium prevents the diffusion of large or hydrophilic molecules, thereby minimising extravasation of systemically derived potentially inflammatory agents and macromolecules. However, some lipoprotein transport including remnants of TRLs occurs across intact and functional endothelium via nonspecific transcytotic processes [40]. This phenomenon is predominantly non-pathogenic, because the lipoproteins are internalized via receptor processes or passage through the basal laminae and exit via the vasa vasorum. However, experimental evidence suggests that prolonged retention of TRLs as a consequence of binding to extracellular matrices and proteoglycans can stimulate chemotaxis and activation of circulating inflammatory cells (Figure 1) [43].

Dietary-lipotoxicity is a term commonly used to broadly describe processes leading to end-organ damage following excess exposure to particular lipids [44]. First identified in the context of fat-induced insulin resistance, the process has since been implicated in a range of chronic diseases and inflammatory disorders. Endothelial cells may be particularly susceptible to the effects of dietary lipids associated with TRLs because of the significant level of lipoprotein processing that occurs via interaction with hydrolytic lipases and, thereafter, the constant exposure to plasma fatty acids and cholesterol. Animal feeding studies have shown that saturated fatty acids and cholesterol-enriched diets increase protein oxidation and lipid peroxidation and significantly alter cell membrane phospholipids and lipid raft composition, key regulators of inflammation [45, 46]. Excess cholesterol can cause mitochondrial dysfunction and trigger apoptotic pathways [47]. Other mechanisms for dietary fat-induced alterations in cell function include stimulation of NADPH-oxidase-derived reactive oxygen species or modulation of mTOR (mammalian target of rapamycin), 


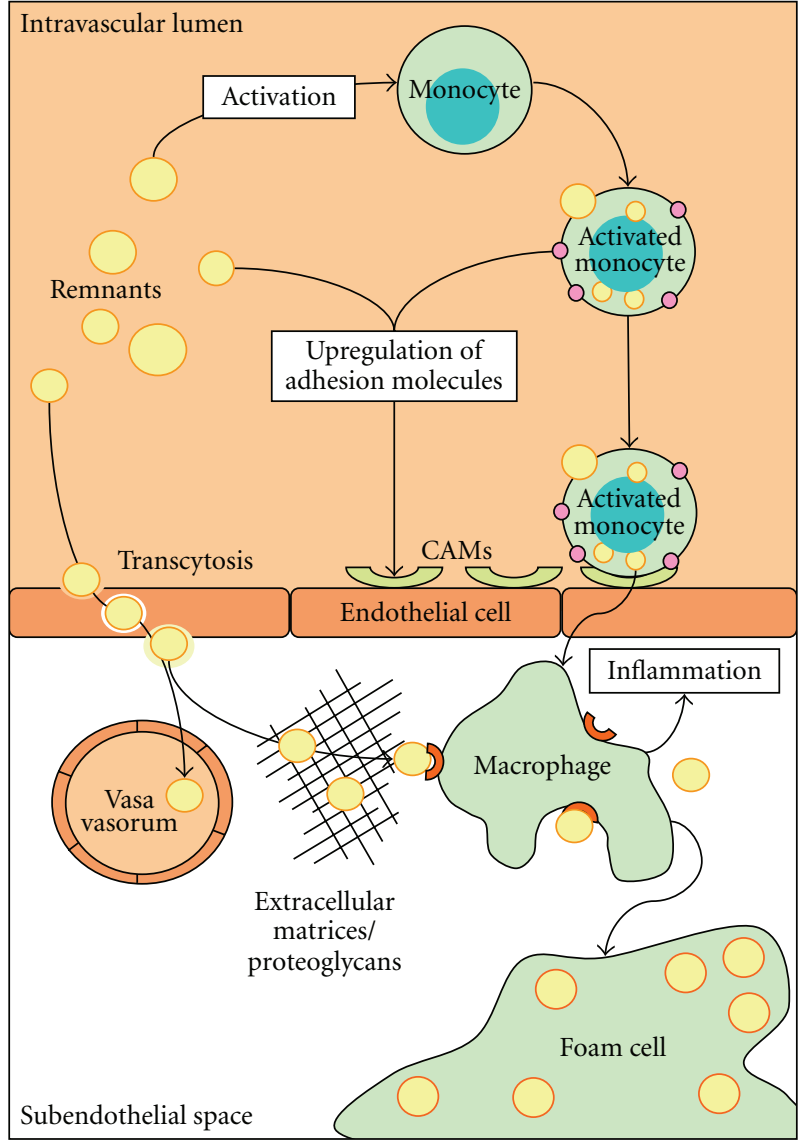

Figure 1: Concept of the initiation of atherosclerosis by remnant lipoproteins: remnants enter the subendothelial space via nonspecific transcytotic processes. This is often a nonpathologic process, because the remnants leave the subendothelial space again via the vasa vasorum. However, retention of remnants may occur in the presence of proteoglycans and excess extracellular matrices. Remnants can be easily taken up by macrophages, in contrast to LDL, which need to become modified first. Circulating remnants themselves also contribute to the presence of subendothelial macrophages. Monocytes can bind and take up remnants, which stimulates the monocytes to become activated. Subsequently, activated monocytes express adhesion molecules on the outer membrane and stimulate the expression of endothelial cellular adhesion molecules (CAMs), which allows monocytes to home on the endothelium and migrate into the subendothelial space. Finally, the macrophages change into highly atherogenic foam cells when lipid uptake exceeds lipid efflux.

a key signal transduction protein that regulates vascular endothelial fenestration [48]. Many other factors have been suggested to participate in the generation of oxidative stress. Paraoxonase 1 (PON-1), a potent antioxidant closely associated with HDL-C, seems to be a key player [49]. During postprandial lipemia, HDL-C tends to decrease, impairing the reverse cholesterol transport and reducing the antiinflammatory properties of HDL-C [50], again providing an extra atherogenic mechanism for postprandial lipemia.

Commensurate with dietary fat modulation, the particle phenotype of lipoproteins determines the susceptibility to subendothelial retention. The heparin sulphate proteoglycans that bind apo B lipoproteins may have greater affinity for TRL remnants because of cooperative apolipoprotein binding domains principally between apo $\mathrm{B}$ and apo $\mathrm{E}$ and exacerbates as a consequence of diabetes [51]. Moreover, apo $\mathrm{E}$ facilitates unabated uptake of remnant lipoproteins by macrophages via alternate pathways without the requisite of lipoprotein modification such as oxidation $[52,53]$.

Nitric oxide (NO) is also one of the key players of endothelium-derived factors, which influences vasomotion, permeability, proliferation, and vascular smooth cell migration [54]. NO-mediated endothelial-dependent vascular relaxation has been shown to be impaired by remnant lipoproteins in studies with isolated vessel segments from rats and pigs in vitro [55]. In human subjects with the metabolic syndrome, but also in healthy subjects, elevated fasting and postprandial TG have been related to increased carotid intima-media thickness (IMT) [56] and reductions in NO-dependent postischemic flow-mediated dilation (FMD) of the brachial artery $[57,58]$. This reduction of FMD correlated with TG and FFA concentrations and was reversible when TG concentrations decreased at the end of the oral fat loading test [57]. Furthermore, postprandial TRLs have been shown to induce the expression of leukocyte adhesion molecules on the endothelium, facilitating recruitment of inflammatory cells [59] and remnant lipoproteins have been found to activate endothelial cells by upregulating COX2 expression and activating intracellular signaling pathways controlled by nuclear factor-kappaB and mitogen-activated protein kinases [60].

\section{Triglyceride-Rich Lipoproteins and Inflammation}

Many inflammatory markers, such as C-reactive protein (CRP), leukocyte count, and complement component 3 (C3), have been associated with CVD [61-66]. Furthermore, several studies with animal models showed reduced plaque formation $[67,68]$ and prevention of endothelial dysfunction [69], when adherence of leukocytes to the endothelium was prevented. These findings support the theory that atherogenesis, in part, starts with leukocyte-endothelium interaction and adherence. Obligatory for this adherence is a cytokine-controlled sequential upregulation of selectins and adhesion molecules on activated leukocytes and endothelial cells [70].

Van Oostrom et al. have shown that postprandially, when TG and glucose rise, neutrophil counts increase with concomitant production of pro-inflammatory cytokines and oxidative stress; and that these changes may contribute to endothelial dysfunction [71, 72]. Furthermore, TG and glucose are able to induce leukocyte activation, as has been shown in vitro $[73,74]$ and ex vivo in hypertriglyceridemic patients [75]. In healthy volunteers and in patients with premature CVD, postprandial lipemia has been associated with the upregulation of leukocyte activation markers $[22,76]$. Fasting leukocytes of patients with CVD have an increased lipid content when compared to controls, and it has been 
suggested that this is due to uptake of chylomicrons [77]. Furthermore, uptake of remnant lipoproteins by primary human monocytes has been demonstrated in experiments in vitro [74]. Leukocytes are also able to take up retinyl esters, as markers of intestinally derived TRLs [78]. Recently, we have shown that apo B binds to neutrophils and monocytes and that postprandial leukocytes transport dietary fatty acids [79]. This opens the possibility that direct activation of leukocytes may occur in the blood by interaction with chylomicrons and their remnants (Figure 1).

Another inflammatory pathway related to CVD and lipid metabolism is the complement system. The C3/acylation stimulating protein- (C3/ASP-) system has been recognized as a regulator of adipose tissue fatty acid metabolism [80]. ASP is identical to the desarginated form of the C3 splitproduct $\mathrm{C} 3 \mathrm{a}$ (C3a-desArg), which is immunologically inactive. The C3/ASP pathway stimulates re-esterification of FFA into TG in adipocytes, reduces adipocyte FFA production by inhibiting hormone sensitive lipase and stimulates glucose uptake by adipocytes, fibroblasts, and muscle cells [80]. C3 is a strong predictor of myocardial infarction [64], and it has been positively associated to obesity, CVD, insulin resistance, the metabolic syndrome [81], fasting and postprandial TG, and hypertension $[2,64]$. Complement components have been shown to colocalize with CRP in atherosclerotic plaques [82] and complement activation also plays a role in the induction of tissue damage after myocardial infarction [83]. Moreover, chylomicrons are the strongest in vitro and in vivo stimulators of adipocyte C3 production via activation of the alternative complement cascade $[66,84]$. A postprandial C3 increment after a fat meal has been shown in healthy subjects, patients with CVD, and patients with familial combined hyperlipidemia $[2,63,66]$. Moreover, this postprandial increment has been related to TG and FFA metabolism [85].

\section{Metabolic Syndrome and Insulin Resistance in Relation to Atherosclerosis and Postprandial Lipemia}

Insulin resistance has also been shown to be associated with impaired vasodilatation, increased oxidative stress and increased concentrations of FFAs, vasoconstrictors, cell adhesion molecules, cytokines, and several other mediators of low-grade inflammation and thrombogenesis [86]. Insulin resistance increases the risk for CVD severalfold compared to the normal population; however, the underlying mechanisms are not completely defined [87]. Insulin resistance often clusters with elevated blood pressure, obesity, central obesity, elevated TG, and low HDL-C. However, whether hyperinsulinemia itself is indeed an independent predictor of CVD has often been debated [87]. A recent metaanalysis by Ruige et al. showed a weak positive association between high insulin levels and CVD events [88]. Another meta-analysis involving 87 studies, which included 951,083 patients based on the definitions of metabolic syndrome by the 2001 National Cholesterol Education Program (NCEP) and 2004 revised National Cholesterol Education Program (rNCEP) demonstrated a 2-fold increase in cardiovascular outcomes and a 1.5-fold increase in all-cause mortality in subjects with the metabolic syndrome [89]. According to the NHANES III data, subjects with metabolic syndrome but without diabetes had a significantly increased prevalence of CVD [90]. However, recently, it was shown that the metabolic syndrome could not improve prediction of intima media thickness progression compared to the sum of its risk components [91]. It is evident that postprandial lipemia is prevalent during conditions of obesity and insulin resistance and may contribute to increased progression of CVD. However, a significant clinical dilemma still exists in diagnosing the early phases of the metabolic syndrome (i.e., prediabetes) and how this impacts on relative risk of CVD. In part, this has been impaired by the continued emphasis on LDL-C, which is often normal during early T2DM, leading to undetected yet insidious progression of CVD $[92,93]$. Indeed, it is interesting to note that the recent revision by the IDF (International Diabetes Federation) has defined the metabolic syndrome independent of LDLC concentrations [94]. In general, in clinical practice, the positive effects of LDL-lowering therapy on atherosclerosis and CVD are nowadays undisputable. While these efforts are well documented, much less is known about the clinical benefits of treating postprandial lipemia, despite increasing evidence supporting a causal role between remnant lipoproteins and the development of CVD [95]. Clinical studies have so far failed to provide a definitive association between impaired postprandial lipoprotein metabolism and the very early phases of insulin resistance and corresponding risk indices. Thus, animal models have to offer further characterization of the early stages of metabolic syndrome in order to understand the metabolic and postprandial profile of this condition. Despite a greater emphasis on the study of CVD risk in the metabolic syndrome, there remains a lack of well-characterized prediabetic models in order to investigate the role of postprandial lipoprotein metabolism in the development of atherosclerosis.

\section{Diet, Lifestyle, Pharmacotherapy, and Postprandial Lipemia}

Postprandial hyperlipidemia has many negative effects on vascular integrity, inflammation, and fatty acid metabolism but can be positively influenced by diet and lifestyle behaviour. Since postprandial lipemia is a physiological response to a fatty meal, it could be predicted that it would be influenced by the amount and type of fat in the diet, and there is strong evidence to support this $[96,97]$. However, in recent years, it has become clear that other lifestyle factors, including dietary protein, fibers and micronutrients, alcohol consumption, exercise, and smoking also play a significant role in the regulation of postprandial lipemia [96]. Postprandial hyperlipidemia may be a link between lifestyle choices and the current alarming rise in the incidence of obesity, insulin resistance, T2DM, and CVD [98]. A summary of the positive and negative effects of lifestyle factors and metabolic diseases on postprandial lipemia is shown in Figure 2. 
Postprandial lipemia is evident after a fat meal containing $>30 \mathrm{~g}$ fat and the rise in plasma TG is dose dependent up to about $80 \mathrm{~g}[96,99]$. Since the average content of Western style meals is $20-40 \mathrm{~g}$ fat and 3-4 meals/day are typically consumed, it can be concluded that postprandial lipemia is likely to be present for $18 \mathrm{~h} /$ day in the Western population [100]. A single fatty meal causes changes in TRL particle characteristics, such as their size, number, and apolipoprotein composition, which depend on the fatty acid composition of the food. The most pronounced lipemia judged by these criteria is caused by a meal containing saturated fatty acids (SFAs), which are found in high amounts in animal fat, followed by monounsaturated fatty acids (MUFA), the main fatty acids in olive oil, with polyunsaturated fatty acids (PUFA), which are found in vegetable (n-6 PUFA) and fish (n-3 PUFA) oils, causing the least pronounced effect [96]. n-3 PUFA have also been shown to cause a lower rise in postprandial lipemia compared to the other types of fat $[96,101,102]$. While acute studies provide useful information, changes in dietary habits need to be sustained in the long term for beneficial effects on health. Both chronic intake and dietary supplementation of n-3 PUFA for periods varying from 4 weeks to 6 months have been shown to decrease postprandial hyperlipidemia due to decreased production of TRLs [103-106]. The effects of fatty acids other than n-3 PUFA on postprandial lipemia are less well defined, but generally, MUFA or n-6 PUFA as compared to SFA have been found to be more beneficial $[96,107,108]$.

In addition to fat, the type of dietary proteins and carbohydrates may also influence postprandial lipemia. Lean red meat, soy protein, casein, and whey protein have all been associated with a reduced postprandial lipemic response $[96,107,109]$, as have indigestible carbohydrates (i.e., dietary fiber) in the form of oat bran, wheat fiber, wheat germ, or psyllium husk $[96,101,110]$. Digestible carbohydrates, on the other hand, appear to have little effect [111] except for fructose which may enhance the postprandial lipemic response if more than $50 \mathrm{~g}$ per day are consumed [112].

Besides macronutrients like fats, carbohydrate, and protein, the diet contains micronutrients including vitamins, carotenoids, plant sterols, and polyphenols found in fruit and vegetables and in beverages such as green tea and red wine, and these are believed to contribute to the protective effect against CVD [113]. Polyphenols in green tea and strawberries have been reported to reduce postprandial lipemia in hyperlipidemic individuals $[114,115]$. In addition, micronutrients in olive oil have been found to reduce postprandial lipemia [116]; however, no evidence for an effect of plant sterols on postprandial lipemia was found in a study with patients on lipid lowering therapy [117].

In addition to changing to a healthier diet, weight loss and increased physical activity are effective lifestyle interventions which reduce postprandial lipemia [118-120]. Exercise before a fat meal, even if only low-to-moderate volume, has been found to decrease postprandial lipemia in many studies [120-125]. Moreover, moderate and high exercise bouts appear to be equally beneficial [126], and a recent meta-analysis of 16 studies concluded that exercise in short bouts is as effective as continuous exercise in

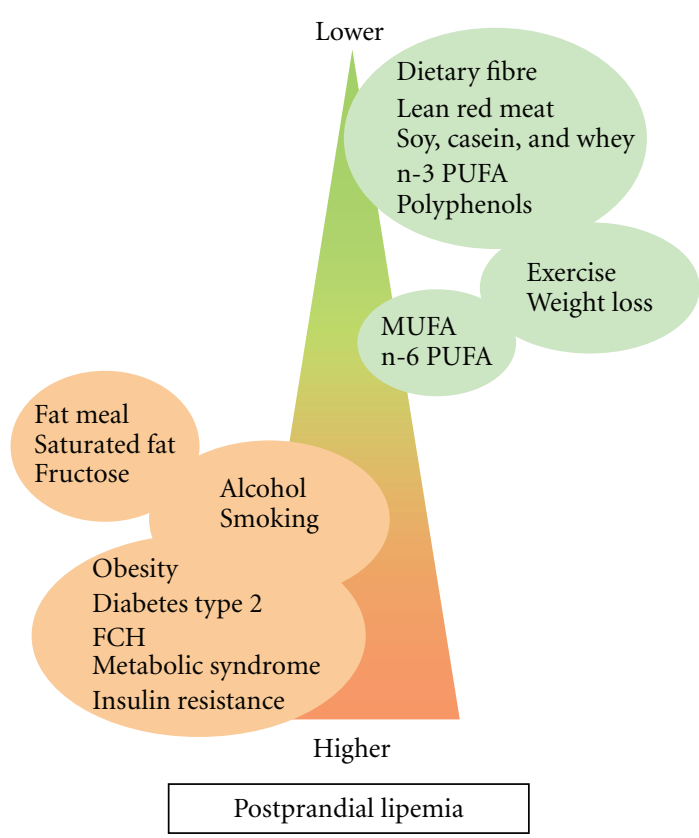

Figure 2: Influence of metabolic diseases and lifestyle factors on postprandial lipemia: factors listed in green circles reduce postprandial lipemia, whereas the factors in red have detrimental effects on postprandial lipemia.

lowering postprandial blood TG concentrations [127]. Lowvolume exercise, however, has been reported to be ineffective in smokers [128], and Bloomer et al. have also reported recently that long-term high-volume exercise had no effect on postprandial lipemia in young, healthy individuals [129]. Combining increased physical activity with dietary changes such as increased n-3 PUFA intake has been found to have a synergistic effect in reducing postprandial lipemia in active individuals [96]. The reduction in postprandial lipemia caused by exercise is believed to be due to increased clearance of TRLs, which is at least partially mediated by an increase in LPL activity [96]. However, current evidence suggests that it is not accompanied by a decrease in the associated postprandial inflammation, as assessed by markers such as $\mathrm{C}$ reactive protein, IL-6, or adhesion molecules [121, 123, 124].

In addition to daily meals and exercise, alcohol and smoking also influence postprandial lipemia. A study by Sharrett et al., which included $>600$ subjects with or without CVD, demonstrated that smoking and alcohol consumption as well as the diet are good predictors of postprandial lipid levels [100]. Despite considerable evidence that low-tomoderate alcohol intake protects against CVD [130], both ethanol and red wine have been shown to cause a marked increase in postprandial lipemia when added to a test meal $[96,131]$. Habitual smokers also have increased postprandial lipemia, and this is thought to be due to impaired clearance of chylomicrons and their remnants [132].

Besides lifestyle interventions, no large improvements have been made in treating postprandial lipemia with pharmacotherapy. Statins are highly effective in reducing LDL cholesterol, but they do not affect TG sufficiently to 
be of clinical relevance in hypertriglyceridemic conditions. However, rosuvastatin is able to reduce the postprandial proinflammatory and procoagulant changes in subjects with CVD [22]. In addition, a decrease in hepatic FFA flux has also been reported [133]. These independent effects from rosuvastatin may protect against CVD when hyperlipidemia is present. In contrast to statins, pharmacotherapy with fibrates is effective in lowering TG concentrations. Despite hypertriglyceridemia being common in the Western population, fibrates are used in only $3.6 \%$ of hypertriglyceridemic subjects [134]. Controversy remains in the effectiveness of fibrates on cardiovascular morbidity and mortality. Recently, a large meta-analysis of fibrates with 45,058 participants was performed [135]. This study showed a modest but significant relative risk reduction of $10 \%$ for major cardiovascular events and $13 \%$ reduction in coronary events, but mortality remained unaltered. While certain drugs are beneficial for improving insulin resistance and potentially postprandial lipemia, in specific groups of patients, the effects on chylomicron and remnant metabolism may be detrimental. For example, rosiglitazone increases postprandial accumulation of atherogenic remnants in HIV-infected patients with lipodystrophy [136]. Therefore, when evaluating the effects of specific pharmacotherapeutic interventions on postprandial lipemia, detailed information on all aspects of the potentially harmful situations will be needed. At this stage, there is no data available on comparative studies regarding lifestyle modification versus lipid lowering therapy on the modulation of postprandial lipemia.

\section{Conclusions}

A residual risk for CVD remains despite aggressive LDL-C lowering by statins, which can partly be explained by postprandial hyperlipidemia, which leads to several metabolic dysfunctions and dietary lipotoxicity via different several mechanisms. First of all, TRLs are able to penetrate the arterial wall leading to endothelial lipid deposits, attraction of monocytes within the subendothelial space, production of inflammatory markers, and oxidative stress. Secondly, obesity worsens insulin resistance which further increases postprandial lipemia, consequently resulting in a vicious circle. Lifestyle interventions like the type of diet, cessation of smoking, and weight loss are effective methods to reduce postprandial lipemia and its related dietary lipotoxicity. Statins also have a beneficial effect on postprandial lipemia. However, at this stage, there are no data available comparing the magnitude of lifestyle interventions with pharmacotherapy on chylomicron metabolism and reduction of CVD.

\section{References}

[1] E. Braunwald, "Shattuck lecture-cardiovascular medicine at the turn of the millennium: triumphs, concerns, and opportunities," New England Journal of Medicine, vol. 337, no. 19, pp. 1360-1369, 1997.

[2] C. J. M. Halkes, H. Van Dijk, P. P. T. De Jaegere et al., "Postprandial increase of complement component 3 in normolipidemic patients with coronary artery disease: effects of expanded-dose simvastatin," Arteriosclerosis, Thrombosis, and Vascular Biology, vol. 21, no. 9, pp. 1526-1530, 2001.

[3] S. Bansal, J. E. Buring, N. Rifai, S. Mora, F. M. Sacks, and P. M. Ridker, "Fasting compared with nonfasting triglycerides and risk of cardiovascular events in women," Journal of the American Medical Association, vol. 298, no. 3, pp. 309-316, 2007.

[4] S. Mora, N. Rifai, J. E. Buring, and P. M. Ridker, "Fasting compared with nonfasting lipids and apolipoproteins for predicting incident cardiovascular events," Circulation, vol. 118, no. 10, pp. 993-1001, 2008.

[5] B. G. Nordestgaard, M. Benn, P. Schnohr, and A. TybjærgHansen, "Nonfasting triglycerides and risk of myocardial infarction, ischemic heart disease, and death in men and women," Journal of the American Medical Association, vol. 298, no. 3, pp. 299-308, 2007.

[6] R. Ross, "Atherosclerosis-an inflammatory disease," New England Journal of Medicine, vol. 340, no. 2, pp. 115-126, 1999.

[7] A. P. Van Beek, H. H. J. J. Van Barlingen, F. C. De RuijterHeijstek et al., "Preferential clearance of apoB-48-containing lipoproteins after heparin- induced lipolysis is modulated by lipoprotein lipase activity," Journal of Lipid Research, vol. 39, no. 2, pp. 322-332, 1998.

[8] T. G. Redgrave, "Formation and metabolism of chylomicrons," International review of physiology, vol. 28, pp. 103130, 1983.

[9] P. Nguyen, V. Leray, M. Diez et al., "Liver lipid metabolism," Journal of Animal Physiology and Animal Nutrition, vol. 92, no. 3, pp. 272-283, 2008.

[10] M. Castro Cabezas, C. J. M. Halkes, S. Meijssen, A. J. H. H. M. Van Oostrom, and D. W. Erkelens, "Diurnal triglyceride profiles: a novel approach to study triglyceride changes," Atherosclerosis, vol. 155, no. 1, pp. 219-228, 2001.

[11] J. P. H. Van Wijk, M. Castro Cabezas, C. J. M. Halkes, and D. W. Erkelens, "Effects of different nutrient intakes on daytime triacylglycerolemia in healthy, normolipemic, freeliving men," American Journal of Clinical Nutrition, vol. 74, no. 2, pp. 171-178, 2001.

[12] G. F. Lewis, N. M. O’Meara, P. A. Soltys et al., "Fasting hypertriglyceridemia in noninsulin-dependent diabetes mellitus is an important predictor of postprandial lipid and lipoprotein abnormalities," Journal of Clinical Endocrinology and Metabolism, vol. 72, no. 4, pp. 934-944, 1991.

[13] J. Denis McGarry, "Dysregulation of fatty acid metabolism in the etiology of type 2 diabetes," Diabetes, vol. 51, no. 1, pp. 7-18, 2002.

[14] F. M. Sacks, M. A. Pfeffer, L. A. Moye et al., "The effect of pravastatin on coronary events after myocardial infarction in patients with average cholesterol levels," New England Journal of Medicine, vol. 335, no. 14, pp. 1001-1009, 1996.

[15] J. R. Downs, M. Clearfield, S. Weis et al., "Primary prevention of acute coronary events with lovastatin in men and women with average cholesterol levels: results of AFCAPS/TexCAPS," Journal of the American Medical Association, vol. 279, no. 20, pp. 1615-1622, 1998.

[16] A. Tonkin, P. Alyward, D. Colquhoun et al., "Prevention of cardiovascular events and death with pravastatin in patients with coronary heart disease and a broad range of initial cholesterol levels," New England Journal of Medicine, vol. 339, no. 19, pp. 1349-1357, 1998.

[17] R. Collins, J. Armitage, S. Parish, P. Sleight, and R. Peto, "MRC/BHF Heart Protection Study of cholesterol lowering 
with simvastatin in 20536 high-risk individuals: a randomised placebo-controlled trial," Lancet, vol. 360, no. 9326, pp. 7-22, 2002.

[18] S. M. Grundy, J. I. Cleeman, C. N. Merz et al., "Implications of recent clinical trials for the National Cholesterol Education Program Adult Treatment Panel III Guidelines," Journal of the American College of Cardiology, vol. 44, no. 3, pp. 720-732, 2004.

[19] M. Castro Cabezas, T. W. A. De Bruin, L. A. W. Kock et al., "Simvastatin improves chylomicron remnant removal in familial combined hyperlipidemia without changing chylomicron conversion," Metabolism, vol. 42, no. 4, pp. 497503, 1993.

[20] M. Castro Cabezas, D. W. Erkelens, L. A. W. Kock, and T. W. A. De Bruin, "Postprandial apolipoprotein B100 and B48 metabolism in familial combined hyperlipidaemia before and after reduction of fasting plasma triglycerides," European Journal of Clinical Investigation, vol. 24, no. 10, pp. 669-678, 1994.

[21] M. Castro Cabezas, C. Verseyden, S. Meijssen, H. Jansen, and D. W. Erkelens, "Effects of atorvastatin on the clearance of triglyceride-rich lipoproteins in familial combined hyperlipidemia," Journal of Clinical Endocrinology and Metabolism, vol. 89, no. 12, pp. 5972-5980, 2004.

[22] A. J. H. H. M. Van Oostrom, H. W. M. Plokker, B. S. Van Asbeck et al., "Effects of rosuvastatin on postprandial leukocytes in mildly hyperlipidemic patients with premature coronary sclerosis," Atherosclerosis, vol. 185, no. 2, pp. 331339, 2006.

[23] S. Fazio, "Management of mixed dyslipidemia in patients with or at risk for cardiovascular disease: a role for combination fibrate therapy," Clinical Therapeutics, vol. 30, no. 2, pp. 294-306, 2008.

[24] P. Deedwania, P. Barter, R. Carmena et al., "Reduction of low-density lipoprotein cholesterol in patients with coronary heart disease and metabolic syndrome: analysis of the Treating to New Targets study," Lancet, vol. 368, no. 9539, pp. 919-928, 2006.

[25] J. W. Su, M. M. Ugo Nzekwu, G. D. C. Ball, and S. D. Proctor, "Postprandial lipemia as an early predictor of cardiovascular complications in childhood obesity," Journal of Clinical Lipidology, vol. 3, no. 2, pp. 78-84, 2009.

[26] J. C. Hogue, B. Lamarche, A. J. Tremblay, J. Bergeron, C. Gagné, and P. Couture, "Evidence of increased secretion of apolipoprotein B-48-containing lipoproteins in subjects with type 2 diabetes," Journal of Lipid Research, vol. 48, no. 6, pp. 1336-1342, 2007.

[27] J. C. L. Mamo and J. R. Wheeler, "Chylomicrons or their remnants penetrate rabbit thoracic aorta as efficiently as do smaller macromolecules, including low-density lipoprotein, high-density lipoprotein, and albumin," Coronary Artery Disease, vol. 5, no. 8, pp. 695-705, 1994.

[28] K. C. W. Yu and J. C. L. Mamo, "Regulation of cholesterol synthesis and esterification in primary cultures of macrophages following uptake of chylomicron remnants," Biochemistry and Molecular Biology International, vol. 41, no. 1, pp. 33-39, 1997.

[29] S. Tomono, S. Kawazu, N. Kato et al., "Uptake of remnant like particles (RLP) in diabetic patients from mouse peritoneal macrophages," Journal of atherosclerosis and thrombosis, vol. 1, no. 2, pp. 98-102, 1994.
[30] K. V. Batt, M. Avella, E. H. Moore, B. Jackson, K. E. Suckling, and K. M. Botham, "Differential effects of lowdensity lipoprotein and chylomicron remnants on lipid accumulation in human macrophages," Experimental Biology and Medicine, vol. 229, no. 6, pp. 528-537, 2004.

[31] M. L. Phillips, C. Pullinger, I. Kroes et al., "A single copy of apolipoprotein B-48 is present on the human chylomicron remnant," Journal of Lipid Research, vol. 38, no. 6, pp. 11701177, 1997.

[32] J. C. L. Mamo, G. F. Watts, P. H. R. Barrett, D. Smith, A. P. James, and P. A. L. Sebely, "Postprandial dyslipidemia in men with visceral obesity: an effect of reduced LDL receptor expression?" American Journal of Physiology, vol. 281, no. 3, pp. E626-E632, 2001.

[33] C. Phillips, G. Murugasu, D. Owens, P. Collins, A. Johnson, and G. H. Tomkin, "Improved metabolic control reduces the number of postprandial apolipoprotein B-48-containing particles in Type 2 diabetes," Atherosclerosis, vol. 148, no. 2, pp. 283-291, 2000.

[34] D. C. Chan, G. F. Watts, P. H. Barrett, J. C. L. Mamo, and T. G. Redgrave, "Markers of triglyceride-rich lipoprotein remnant metabolism in visceral obesity," Clinical Chemistry, vol. 48, no. 2, pp. 278-283, 2002.

[35] J. S. Cohn, C. Marcoux, and J. Davignon, "Detection, quantification, and characterization of potentially atherogenic triglyceride-rich remnant lipoproteins," Arteriosclerosis, Thrombosis, and Vascular Biology, vol. 19, no. 10, pp. 24742486, 1999.

[36] M. Castro Cabezas and D. W. Erkelens, "The direct way from gut to vessel wall: atheroinitiation," European Journal of Clinical Investigation, vol. 28, no. 6, pp. 504-505, 1998.

[37] C. A. Dane-Stewart, G. F. Watts, J. C. L. Mamo, S. B. Dimmitt, P. H. R. Barrett, and T. G. Redgrave, "Elevated apolipoprotein B-48 and remnant-like particle-cholesterol in heterozygous familial hypercholesterolaemia," European Journal of Clinical Investigation, vol. 31, no. 2, pp. 113-117, 2001.

[38] G. F. Watts, P. H. R. Barrett, A. D. Marais et al., "Chylomicron remnant metabolism in familial hypercholesterolaemia studied with a stable isotope breath test," Atherosclerosis, vol. 157, no. 2, pp. 519-523, 2001.

[39] S. D. Proctor, D. F. Vine, and J. C. L. Mamo, "Arterial retention of apolipoprotein B48- and B100-containing lipoproteins in atherogenesis," Current Opinion in Lipidology, vol. 13, no. 5, pp. 461-470, 2002.

[40] S. D. Proctor, D. F. Vine, and J. C. L. Mamo, "Arterial permeability and efflux of apolipoprotein B-containing lipoproteins assessed by in situ perfusion and three-dimensional quantitative confocal microscopy," Arteriosclerosis, Thrombosis, and Vascular Biology, vol. 24, no. 11, pp. 2162-2167, 2004.

[41] I. J. Goldberg, R. H. Eckel, and R. McPherson, "Triglycerides and heart disease: still a hypothesis?" Arteriosclerosis, Thrombosis, and Vascular Biology, vol. 31, no. 8, pp. 1716-1725, 2011.

[42] N. J. Abbott, A. A. K. Patabendige, D. E. M. Dolman, S. R. Yusof, and D. J. Begley, "Structure and function of the bloodbrain barrier," Neurobiology of Disease, vol. 37, no. 1, pp. 13$25,2010$.

[43] K. C. Yu and A. D. Cooper, "Postprandial lipoproteins and atherosclerosis," Front Biosci, vol. 6, pp. D332-D354, 2001.

[44] J. E. Schaffer, "Lipotoxicity: when tissues overeat," Current Opinion in Lipidology, vol. 14, no. 3, pp. 281-287, 2003. 
[45] T. Ronti, G. Lupattelli, and E. Mannarino, "The endocrine function of adipose tissue: an update," Clinical Endocrinology, vol. 64, no. 4, pp. 355-365, 2006.

[46] R. H. Unger, "Lipotoxicity in the pathogenesis of obesitydependent NIDDM: genetic and clinical implications," Diabetes, vol. 44, no. 8, pp. 863-870, 1995.

[47] P. M. Yao and I. Tabas, "Free cholesterol loading of macrophages is associated with widespread mitochondrial dysfunction and activation of the mitochondrial apoptosis pathway," Journal of Biological Chemistry, vol. 276, no. 45, pp. 42468-42476, 2001.

[48] M. Laplante and D. M. Sabatini, "An emerging role of mTOR in lipid biosynthesis," Current Biology, vol. 19, no. 22, pp. R1046-R1052, 2009.

[49] B. Mackness, R. Quarck, W. Verreth, M. Mackness, and P. Holvoet, "Human paraoxonase-1 overexpression inhibits atherosclerosis in a mouse model of metabolic syndrome," Arteriosclerosis, Thrombosis, and Vascular Biology, vol. 26, no. 7, pp. 1545-1550, 2006.

[50] T. Vaisar, S. Pennathur, P. S. Green et al., "Shotgun proteomics implicates protease inhibition and complement activation in the antiinflammatory properties of HDL," Journal of Clinical Investigation, vol. 117, no. 3, pp. 746-756, 2007.

[51] L. R. Tannock and A. Chait, "Lipoprotein-matrix interactions in macrovascular disease in diabetes," Frontiers in Bioscience, vol. 9, pp. 1728-1742, 2004.

[52] K. M. Botham, E. H. Moore, C. De Pascale, and F. Bejta, "The induction of macrophage foam cell formation by chylomicron remnants," Biochemical Society Transactions, vol. 35, no. 3, pp. 454-458, 2007.

[53] C. De Pascale, M. Avella, J. S. Perona, V. Ruiz-Gutierrez, C. P. D. Wheeler-Jones, and K. M. Botham, "Fatty acid composition of chylomicron remnant-like particles influences their uptake and induction of lipid accumulation in macrophages," FEBS Journal, vol. 273, no. 24, pp. 5632-5640, 2006.

[54] A. M. Lefer, "Nitric oxide: nature's naturally occurring leukocyte inhibitor," Circulation, vol. 95, no. 3, pp. 553-554, 1997.

[55] J. Dalla-Riva, E. Garonna, J. Elliott, K. M. Botham, and C. P. Wheeler-Jones, "Endothelial cells as targets for chylomicron remnants," Atherosclerosis Supplements, vol. 11, no. 1, pp. 31$37,2010$.

[56] S. Boquist, G. Ruotolo, R. Tang et al., "Alimentary lipemia, postprandial triglyceride-rich lipoproteins, and common carotid intima-media thickness in healthy, middle-aged men," Circulation, vol. 100, no. 7, pp. 723-728, 1999.

[57] S. Marchesi, G. Lupattelli, G. Schillaci et al., "Impaired flowmediated vasoactivity during post-prandial phase in young healthy men," Atherosclerosis, vol. 153, no. 2, pp. 397-402, 2000.

[58] R. A. Vogel, M. C. Corretti, and G. D. Plotnick, "Effect of a single high-fat meal on endothelial function in healthy subjects," American Journal of Cardiology, vol. 79, no. 3, pp. 350-354, 1997.

[59] P. J. Lefèbvre and A. J. Scheen, "The postprandial state and risk of cardiovascular disease," Diabetic Medicine, vol. 15, no. 4, pp. S63-S68, 1998.

[60] C. P. D. Wheeler-Jones, "Chylomicron remnants: mediators of endothelial dysfunction?" Biochemical Society Transactions, vol. 35, no. 3, pp. 442-445, 2007.

[61] J. Danesh, P. Whincup, M. Walker et al., "Low grade inflammation and coronary heart disease: prospective study and updated meta-analyses," British Medical Journal, vol. 321, no. 7255, pp. 199-204, 2000.

[62] G. D. Friedman, A. L. Klatsky, and A. B. Siegelaub, "The leukocyte count as a predictor of myocardial infarction," New England Journal of Medicine, vol. 290, no. 23, pp. 1275-1278, 1974.

[63] S. Meijssen, H. Van Dijk, C. Verseyden, D. W. Erkelens, and M. Castro Cabezas, "Delayed and exaggerated postprandial complement component 3 response in familial combined hyperlipidemia," Arteriosclerosis, Thrombosis, and Vascular Biology, vol. 22, no. 5, pp. 811-816, 2002.

[64] A. Muscari, G. Massarelli, L. Bastagli et al., "Relationship of serum C3 to fasting insulin, risk factors and previous ischaemic events in middle-aged men," European Heart Journal, vol. 21, no. 13, pp. 1081-1090, 2000.

[65] M. I. Schmidt, B. B. Duncan, A. R. Sharrett et al., "Markers of inflammation and prediction of diabetes mellitus in adults (Atherosclerosis Risk in Communities study): a cohort study," Lancet, vol. 353, no. 9165, pp. 1649-1652, 1999.

[66] C. Verseyden, S. Meijssen, H. Van Dijk, H. Jansen, and M. Castro Cabezas, "Effects of atorvastatin on fasting and postprandial complement component 3 response in familial combined hyperlipidemia," Journal of Lipid Research, vol. 44, no. 11, pp. 2100-2108, 2003.

[67] E. E. Eriksson, X. Xie, J. Werr, P. Thoren, and L. Lindbom, "Direct viewing of atherosclerosis in vivo: plaque invasion by leukocytes is initiated by the endothelial selectins," FASEB Journal, vol. 15, no. 7, pp. 1149-1157, 2001.

[68] Y. Huo and K. Ley, "Adhesion molecules and atherogenesis," Acta Physiologica Scandinavica, vol. 173, no. 1, pp. 35-43, 2001.

[69] T. Murohara, M. Buerke, and A. M. Lefer, "Polymorphonuclear leukocyte-induced vasocontraction and endothelial dysfunction: role of selectins," Arteriosclerosis and Thrombosis, vol. 14, no. 9, pp. 1509-1519, 1994.

[70] R. A. Worthylake and K. Burridge, "Leukocyte transendothelial migration: orchestrating the underlying molecular machinery," Current Opinion in Cell Biology, vol. 13, no. 5, pp. 569-577, 2001.

[71] A. J. H. H. M. Van Oostrom, T. P. Sijmonsma, T. J. Rabelink, B. S. Van Asbeck, and M. Castro Cabezas, "Postprandial leukocyte increase in healthy subjects," Metabolism, vol. 52, no. 2, pp. 199-202, 2003.

[72] A. J. H. H. M. Van Oostrom, T. P. Sijmonsma, C. Verseyden et al., "Postprandial recruitment of neutrophils may contribute to endothelial dysfunction," Journal of Lipid Research, vol. 44, no. 3, pp. 576-583, 2003.

[73] G. Wanten, S. Van Emst-de Vries, T. Naber, and P. Willems, "Nutritional lipid emulsions modulate cellular signaling and activation of human neutrophils," Journal of Lipid Research, vol. 42, no. 3, pp. 428-436, 2001.

[74] C. Bentley, N. Hathaway, J. Widdows et al., "Influence of chylomicron remnants on human monocyte activation in vitro," Nutrition, Metabolism and Cardiovascular Diseases. In press.

[75] K. Hiramatsu and S. Arimori, "Increased superoxide production by mononuclear cells of patients with hypertriglyceridemia and diabetes," Diabetes, vol. 37, no. 6, pp. 832-837, 1988.

[76] A. J. H. H. M. Van Oostrom, T. J. Rabelink, C. Verseyden et al., "Activation of leukocytes by postprandial lipemia in healthy volunteers," Atherosclerosis, vol. 177, no. 1, pp. 175$182,2004$. 
[77] V. V. Tertov, O. S. Kalenich, and A. N. Orekhov, "Lipid-laden white blood cells in the circulation of patients with coronary heart disease," Experimental and Molecular Pathology, vol. 57, no. 1, pp. 22-28, 1992.

[78] B. Skrede, R. Blomhoff, G. M. Maelandsmo, L. Ose, O. Myklebost, and K. R. Norum, "Uptake of chylomicron remnant retinyl esters in human leukocytes in vivo," European Journal of Clinical Investigation, vol. 22, no. 4, pp. 229-234, 1992.

[79] A. Alipour, A. J. H. H. M. Van Oostrom, A. Izraeljan et al., "Leukocyte activation by triglyceride-rich lipoproteins," Arteriosclerosis, Thrombosis, and Vascular Biology, vol. 28, no. 4, pp. 792-797, 2008.

[80] K. Cianflone, Z. Xia, and L. Y. Chen, "Critical review of acylation-stimulating protein physiology in humans and rodents," Biochimica et Biophysica Acta, vol. 1609, no. 2, pp. 127-143, 2003.

[81] A. J. H. H. M. van Oostrom, A. Alipour, T. W. M. Plokker, A. D. Sniderman, and M. Castro Cabezas, "The metabolic syndrome in relation to complement component 3 and postprandial lipemia in patients from an outpatient lipid clinic and healthy volunteers," Atherosclerosis, vol. 190, no. 1, pp. 167-173, 2007.

[82] J. Torzewski, M. Torzewski, D. E. Bowyer et al., "C-Reactive protein frequently colocalizes with the terminal complement complex in the intima of early atherosclerotic lesions of human coronary arteries," Arteriosclerosis, Thrombosis, and Vascular Biology, vol. 18, no. 9, pp. 1386-1392, 1998.

[83] M. Griselli, J. Herbert, W. L. Hutchinson et al., "C-reactive protein and complement are important mediators of tissue damage in acute myocardial infarction," Journal of Experimental Medicine, vol. 190, no. 12, pp. 1733-1739, 1999.

[84] T. Scantlebury, A. D. Sniderman, and K. Cianflone, "Regulation by retinoic acid of acylation-stimulating protein and complement C3 in human adipocytes," Biochemical Journal, vol. 356, no. 2, pp. 445-452, 2001.

[85] C. J. M. Halkes, H. Van Dijk, C. Verseyden et al., "Gender differences in postprandial ketone bodies in normolipidemic subjects and in untreated patients with familial combined hyperlipidemia," Arteriosclerosis, Thrombosis, and Vascular Biology, vol. 23, no. 10, pp. 1875-1880, 2003.

[86] M. Laakso, "Cardiovascular disease in type 2 diabetes from population to man to mechanisms: the Kelly West award lecture 2008," Diabetes Care, vol. 33, no. 2, pp. 442-449, 2010.

[87] M. Laakso, "Insulin resistance and coronary heart disease," Current Opinion in Lipidology, vol. 7, no. 4, pp. 217-226, 1996.

[88] J. B. Ruige, W. J. J. Assendelft, J. M. Dekker, P. J. Kostense, R. J. Heine, and L. M. Bouter, "Insulin and risk of cardiovascular disease: a meta-analysis," Circulation, vol. 97, no. 10, pp. 9961001, 1998.

[89] S. Mottillo, K. B. Filion, J. Genest et al., "The metabolic syndrome and cardiovascular risk: a systematic review and meta-analysis," Journal of the American College of Cardiology, vol. 56, no. 14, pp. 1113-1132, 2010.

[90] C. M. Alexander, P. B. Landsman, S. M. Teutsch, and S. M. Haffner, "NCEP-defined metabolic syndrome, diabetes, and prevalence of coronary heart disease among NHANES III participants age 50 years and older," Diabetes, vol. 52, no. 5, pp. 1210-1214, 2003.

[91] J. Koskinen, M. Kähönen, J. S. A. Viikari et al., "Conventional cardiovascular risk factors and metabolic syndrome in predicting carotid intima-media thickness progression in young adults: the cardiovascular risk in young finns study," Circulation, vol. 120, no. 3, pp. 229-236, 2009.
[92] D. E. Moller and K. D. Kaufman, "Metabolic syndrome: a clinical and molecular perspective," Annual Review of Medicine, vol. 56, pp. 45-62, 2005.

[93] R. H. Eckel, S. M. Grundy, and P. Z. Zimmet, "The metabolic syndrome," Lancet, vol. 365, no. 9468, pp. 1415-1428, 2005.

[94] K. G. M. M. Alberti, P. Zimmet, and J. Shaw, "The metabolic syndrome-a new worldwide definition," Lancet, vol. 366, no. 9491, pp. 1059-1062, 2005.

[95] D. R. Sullivan, D. S. Celermajer, D. G. Le Couteur, and C. W. Lam, "The vascular implications of post-prandial lipoprotein metabolism," Clinical Biochemistry Reviews, vol. 25, no. 1, pp. 19-30, 2004.

[96] J. Lopez-Miranda, C. Williams, and D. Larion, "Dietary, physiological, genetic and pathological influences on postprandial lipid metabolism," British Journal of Nutrition, vol. 98, no. 3, pp. 458-473, 2007.

[97] D. Lairon and C. Defoort, "Effects of nutrients on postprandial lipemia," Current Vascular Pharmacology, vol. 9, no. 3, pp. 309-312, 2011.

[98] E. Bravo, M. Napolitano, and K. M. Botham, "Postprandial lipid metabolism: the missing link between life-style habits and the increasing incidence of metabolic diseases in western countries?" Open Translational Medicine Journal, vol. 2, pp. $1-13,2010$.

[99] C. Dubois, G. Beaumier, C. Juhel et al., "Effects of graded amounts $(0-50 \mathrm{~g})$ of dietary fat on postprandial lipemia and lipoproteins in normolipidemic adults," American Journal of Clinical Nutrition, vol. 67, no. 1, pp. 31-38, 1998.

[100] A. R. Sharrett, G. Heiss, L. E. Chambless et al., "Metabolic and lifestyle determinants of postprandial lipemia differ from those of fasting triglycerides the Atherosclerosis Risk in Communities (ARIC) study," Arteriosclerosis, Thrombosis, and Vascular Biology, vol. 21, no. 2, pp. 275-281, 2001.

[101] D. Lairon, B. Play, and D. Jourdheuil-Rahmani, "Digestible and indigestible carbohydrates: interactions with postprandial lipid metabolism," Journal of Nutritional Biochemistry, vol. 18, no. 4, pp. 217-227, 2007.

[102] A. Zampelas, A. S. Peel, B. J. Gould, J. Wright, and C. M. Williams, "Polyunsaturated fatty acids of the n-6 and n-3 series: effects on postprandial lipid and apolipoprotein levels in healthy men," European Journal of Clinical Nutrition, vol. 48, no. 12, pp. 842-848, 1994.

[103] C. M. Williams, F. Moore, L. Morgan, and J. Wright, "Effects of n-3 fatty acids on postprandial triacylglycerol and hormone concentrations in normal subjects," British Journal of Nutrition, vol. 68, no. 3, pp. 655-666, 1992.

[104] W. S. Harris and F. Muzio, "Fish oil reduces postprandial triglyceride concentrations without accelerating lipidemulsion removal rates," American Journal of Clinical Nutrition, vol. 58, no. 1, pp. 68-74, 1993.

[105] D. S. Kelley, D. Siegel, M. Vemuri, and B. E. Mackey, "Docosahexaenoic acid supplementation improves fasting and postprandial lipid profiles in hypertriglyceridemic men," American Journal of Clinical Nutrition, vol. 86, no. 2, pp. 324333, 2007.

[106] S. Westphal, M. Orth, A. Ambrosch, K. Osmundsen, and C. Luley, "Postprandial chylomicrons and VLDLs in severe hypertriacylglycerolemia are lowered more effectively than are chylomicron remnants after treatment with n-3 fatty acids," American Journal of Clinical Nutrition, vol. 71, no. 4, pp. 914-920, 2000. 
[107] D. Lairon, "Macronutrient intake and modulation on chylomicron production and clearance," Atherosclerosis Supplements, vol. 9, no. 2, pp. 45-48, 2008.

[108] A. Lozano, P. Perez-Martinez, J. Delgado-Lista et al., "Body mass interacts with fat quality to determine the postprandial lipoprotein response in healthy young adults," Nutrition, Metabolism and Cardiovascular Disease. In press.

[109] L. S. Mortensen, M. L. Hartvigsen, L. J. Brader et al., "Differential effects of protein quality on postprandial lipemia in response to a fat-rich meal in type 2 diabetes: comparison of whey, casein, gluten, and cod protein," American Journal of Clinical Nutrition, vol. 90, no. 1, pp. 41-48, 2009.

[110] A. Khossousi, C. W. Binns, S. S. Dhaliwal, and S. Pal, "The acute effects of psyllium on postprandial lipaemia and thermogenesis in overweight and obese men," British Journal of Nutrition, vol. 99, no. 5, pp. 1068-1075, 2008.

[111] A. Harbis, S. Perdreau, S. Vincent-Baudry et al., "Glycemic and insulinemic meal responses modulate postprandial hepatic and intestinal lipoprotein accumulation in obese, insulin-resistant subjects," American Journal of Clinical Nutrition, vol. 80, no. 4, pp. 896-902, 2004.

[112] G. Livesey and R. Taylor, "Fructose consumption and consequences for glycation, plasma triacylglycerol, and body weight: meta-analyses and meta-regression models of intervention studies," American Journal of Clinical Nutrition, vol. 88, no. 5, pp. 1419-1437, 2008.

[113] A. Mente, L. De Koning, H. S. Shannon, and S. S. Anand, "A systematic review of the evidence supporting a causal link between dietary factors and coronary heart disease," Archives of Internal Medicine, vol. 169, no. 7, pp. 659-669, 2009.

[114] A. Basu and E. A. Lucas, "Mechanisms and effects of green tea on cardiovascular health," Nutrition Reviews, vol. 65, no. 8, pp. 361-375, 2007.

[115] B. Burton-Freeman, A. Linares, D. Hyson, and T. Kappagoda, "Strawberry modulates LDL oxidation and postprandial lipemia in response to high-fat meal in overweight hyperlipidemic men and women," Journal of the American College of Nutrition, vol. 29, no. 1, pp. 46-54, 2010.

[116] R. Abia, Y. M. Pacheco, J. S. Perona, E. Montero, F. J. G. Muriana, and V. Ruiz-Gutiérrez, "The metabolic availability of dietary triacylglycerols from two high oleic oils during the postprandial period does not depend on the amount of oleic acid ingested by healthy men," Journal of Nutrition, vol. 131, no. 1, pp. 59-65, 2001.

[117] M. Castro Cabezas, J. H. M. de Vries, A. J. H. H. M. Van Oostrom, J. Iestra, and W. A. van Staveren, "Effects of a stanol-enriched diet on plasma cholesterol and triglycerides in patients treated with statins," Journal of the American Dietetic Association, vol. 106, no. 10, pp. 1564-1569, 2006.

[118] L. T. Braun, "Cholesterol and triglyceride management: "If i take my medication, can I Eat what I Want?"', Journal of Cardiovascular Nursing, vol. 25, no. 3, pp. 241-246, 2010.

[119] M. Maraki, F. Magkos, N. Christodoulou et al., "One day of moderate energy deficit reduces fasting and postprandial triacylglycerolemia in women: the role of calorie restriction and exercise," Clinical Nutrition, vol. 29, no. 4, pp. 459-463, 2010.

[120] M. I. Maraki, N. Aggelopoulou, N. Christodoulou et al., "Lifestyle intervention leading to moderate weight loss normalizes postprandial triacylglycerolemia despite persisting obesity," Obesity, vol. 19, no. 5, pp. 968-976, 2011.
[121] O. J. MacEneaney, M. Harrison, D. J. O'Gorman, E. V. Pankratieva, P. L. O'Connor, and N. M. Moyna, "Effect of prior exercise on postprandial lipemia and markers of inflammation and endothelial activation in normal weight and overweight adolescent boys," European Journal of Applied Physiology, vol. 106, no. 5, pp. 721-729, 2009.

[122] Z. K. Pafili, G. C. Bogdanis, N. V. Tsetsonis, and M. Maridaki, "Postprandial lipemia 16 and 40 hours after low-volume eccentric resistance exercise," Medicine and Science in Sports and Exercise, vol. 41, no. 2, pp. 375-382, 2009.

[123] M. J. Dekker, T. E. Graham, T. C. Ooi, and L. E. Robinson, "Exercise prior to fat ingestion lowers fasting and postprandial VLDL and decreases adipose tissue IL-6 and GIP receptor mRNA in hypertriacylglycerolemic men," Journal of Nutritional Biochemistry, vol. 21, no. 10, pp. 983-990, 2010.

[124] M. Miyashita, S. F. Burns, and D. J. Stensel, "Acute effects of accumulating exercise on postprandial lipemia and Creactive protein concentrations in young men," International Journal of Sport Nutrition and Exercise Metabolism, vol. 19, no. 6, pp. 569-582, 2009.

[125] C. Gavin, R. J. Sigal, M. Cousins et al., "Resistance exercise but not aerobic exercise lowers remnant-like lipoprotein particle cholesterol in type 2 diabetes: a randomized controlled trial," Atherosclerosis, vol. 213, no. 2, pp. 552-557, 2010.

[126] A. Singhal, J. L. Trilk, N. T. Jenkins, K. A. Bigelman, and K. J. Cureton, "Effect of intensity of resistance exercise on postprandial lipemia," Journal of Applied Physiology, vol. 106, no. 3, pp. 823-829, 2009.

[127] M. H. Murphy, S. N. Blair, and E. M. Murtagh, "Accumulated versus continuous exercise for health benefit: a review of empirical studies," Sports Medicine, vol. 39, no. 1, pp. 29-43, 2009.

[128] R. J. Bloomer and K. H. Fisher-Wellman, "Postprandial oxidative stress in exercise trained and sedentary cigarette smokers," International Journal of Environmental Research and Public Health, vol. 6, no. 2, pp. 579-591, 2009.

[129] R. J. Bloomer, K. H. Fisher-Wellman, and H. K. Bell, "The effect of long-term, high-volume aerobic exercise training on postprandial lipemia and oxidative stress," Physician and Sportsmedicine, vol. 38, no. 1, pp. 64-71, 2010.

[130] J. H. O'Keefe, N. M. Gheewala, and J. O. O'Keefe, "Dietary strategies for improving post-prandial glucose, lipids, inflammation, and cardiovascular health," Journal of the American College of Cardiology, vol. 51, no. 3, pp. 249255, 2008.

[131] M. Naissides, J. C. L. Mamo, A. P. James, and S. Pal, "The effect of acute red wine polyphenol consumption on postprandial lipaemia in postmenopausal women," Atherosclerosis, vol. 177, no. 2, pp. 401-408, 2004.

[132] N. Mero, M. Syvanne, B. Eliasson, U. Smith, and M. R. Taskinen, "Postprandial elevation of apoB-48-containing triglyceride-rich particles and retinyl esters in normolipemic males who smoke," Arteriosclerosis, Thrombosis, and Vascular Biology, vol. 17, no. 10, pp. 2096-2102, 1997.

[133] S. Meijssen, R. J. Derksen, S. Bilecen, D. W. Erkelens, and M. Castro Cabezas, "In vivo modulation of plasma free fatty acids in patients with Familial Combined Hyperlipidemia using Lipid-Lowering medication," Journal of Clinical Endocrinology and Metabolism, vol. 87, no. 4, pp. 1576-1580, 2002.

[134] E. S. Ford, C. Li, G. Zhao, W. S. Pearson, and A. H. Mokdad, "Hypertrigly ceridemia and Its pharmacologic treatment among US adults," Archives of Internal Medicine, vol. 169, no. 6, pp. 572-578, 2009. 
[135] M. Jun, C. Foote, J. Lv et al., "Effects of fibrates on cardiovascular outcomes: a systematic review and metaanalysis," The Lancet, vol. 375, no. 9729, pp. 1875-1884, 2010.

[136] J. P. H. Van Wijk, A. I. M. Hoepelman, E. J. P. De Koning, G. Dallinga-Thie, T. J. Rabelink, and M. Castro Cabezas, "Differential effects of rosiglitazone and metformin on postprandial lipemia in patients with HIV-lipodystrophy," Arteriosclerosis, Thrombosis, and Vascular Biology, vol. 31, no. 1, pp. 228-233, 2011. 


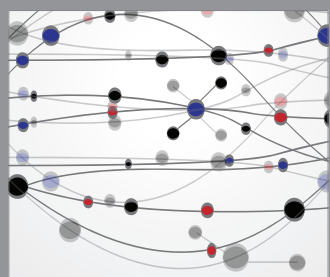

The Scientific World Journal
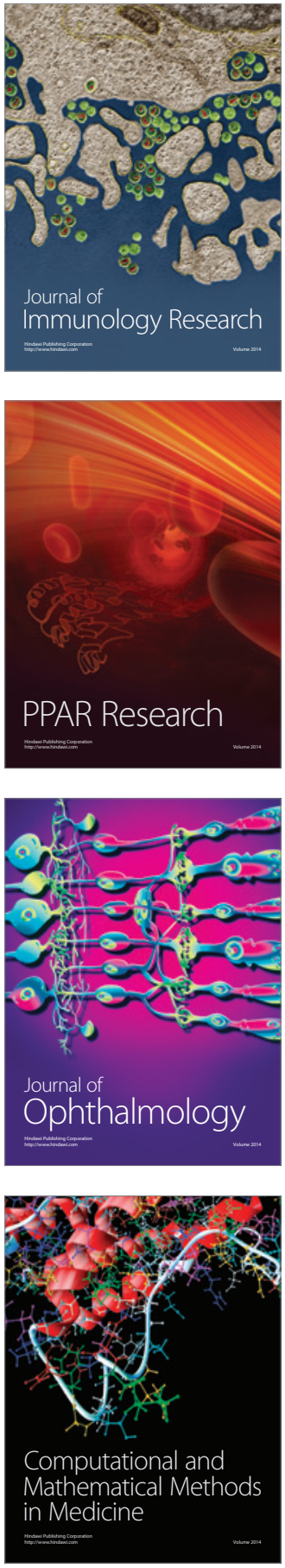

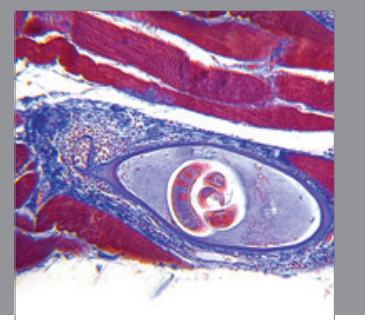

Gastroenterology

Research and Practice
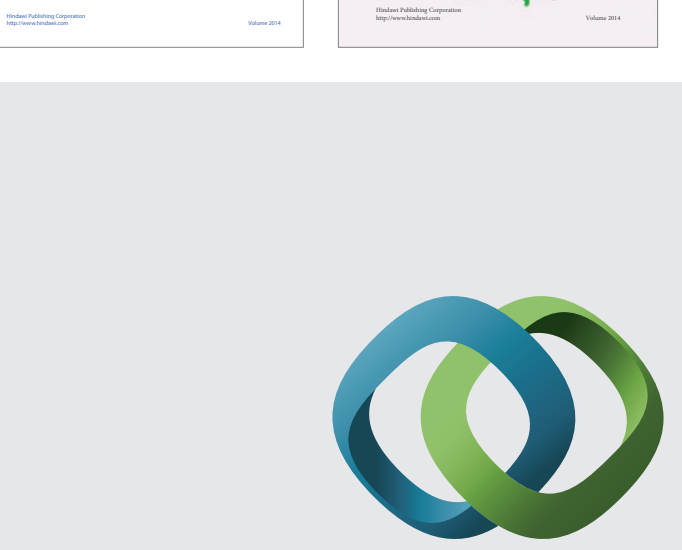

\section{Hindawi}

Submit your manuscripts at

http://www.hindawi.com
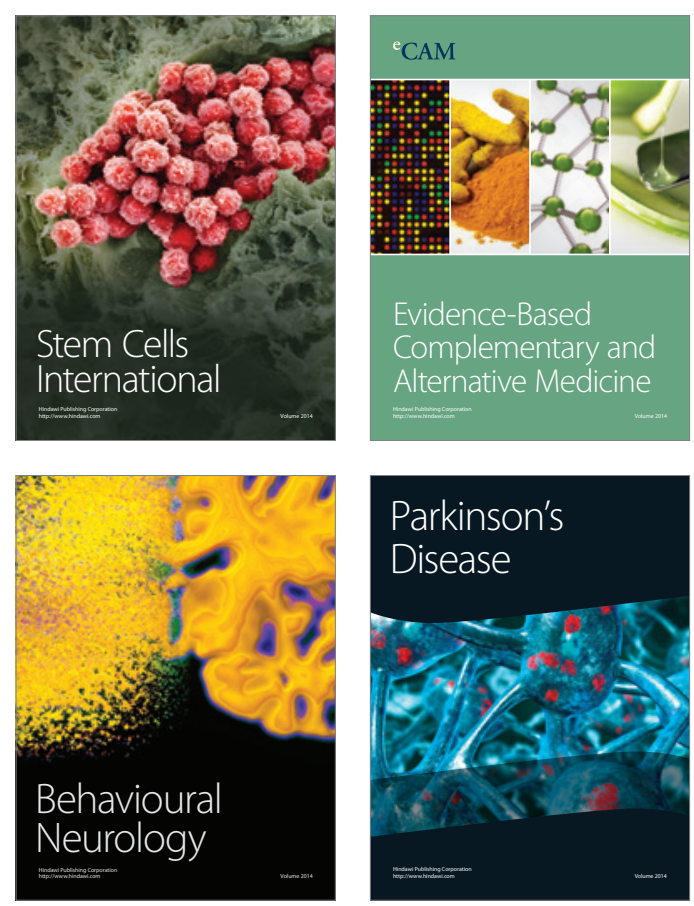

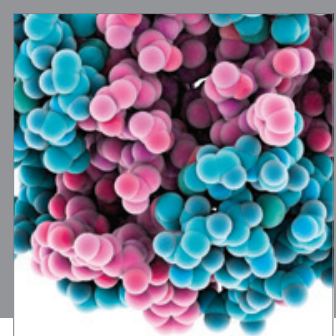

Journal of
Diabetes Research

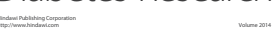

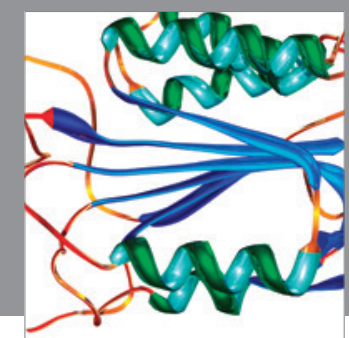

Disease Markers
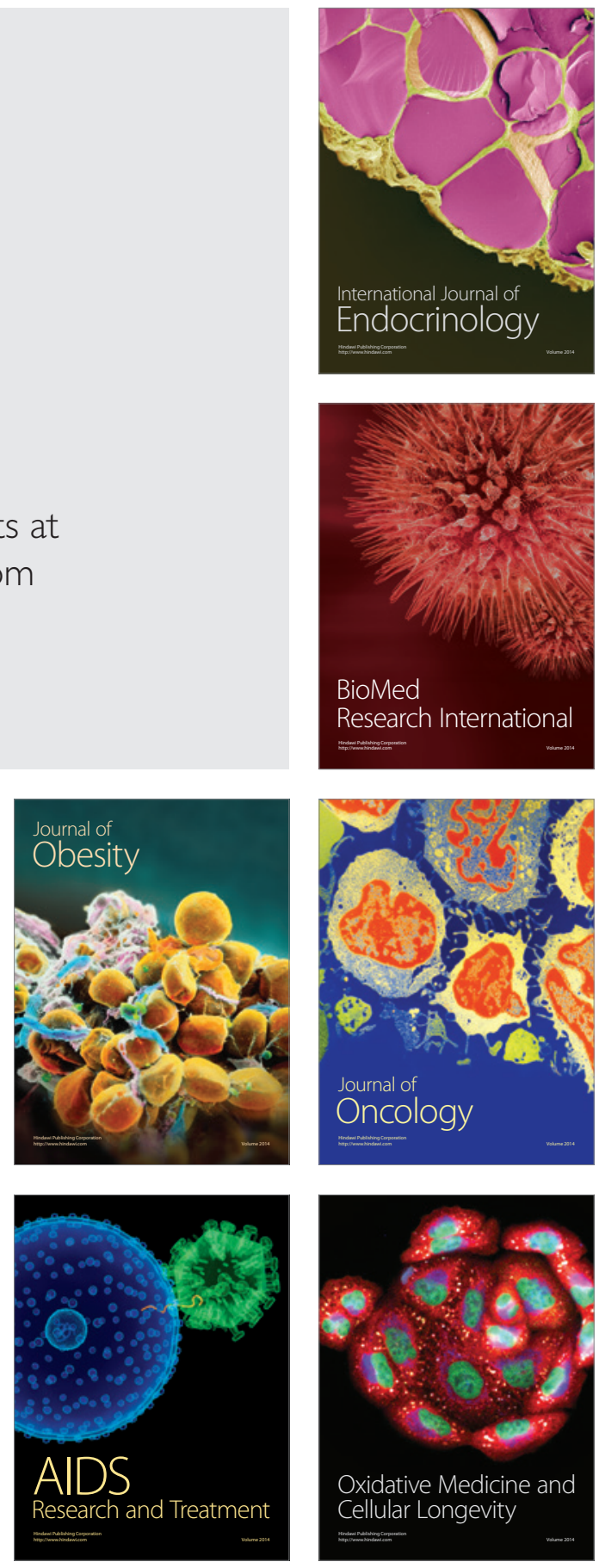